Western University

Scholarship@Western

Physical Therapy Publications

Physical Therapy School

$10-1-2017$

\title{
Understanding participation of children with cerebral palsy in family and recreational activities.
}

Mohammed S Alghamdi

Lisa A Chiarello

Robert J Palisano

Sarah W McCoy

Follow this and additional works at: https://ir.lib.uwo.ca/ptpub

Part of the Physical Therapy Commons

Citation of this paper:

Alghamdi, Mohammed S; Chiarello, Lisa A; Palisano, Robert J; and McCoy, Sarah W, "Understanding participation of children with cerebral palsy in family and recreational activities." (2017). Physical Therapy Publications. 42.

https://ir.lib.uwo.ca/ptpub/42 


\section{Title:}

Understanding Participation of Children with Cerebral Palsy in Family and Recreational Activities

\section{Authors' names:}

Mohammed S. Alghmadi ${ }^{\text {ac }}$; Lisa A. Chiarello ${ }^{\text {a }}$; Robert J. Palisano ${ }^{\text {a }}$; Sarah W. McCoy ${ }^{b}$

${ }^{a}$ Drexel University, Department of Physical Therapy and Rehabilitation Sciences, 1601

Cherry Street, Mail Stop 7502, Philadelphia, PA 19102, USA

${ }^{\mathrm{b}}$ University of Washington, Department of Rehabilitation Medicine, Box 356490, 1959 NE

Pacific St, Seattle, WA 98195-6490, USA

${ }^{c}$ Umm Al-Qura University, Department of Physical Therapy, P.O. Box 715, Makkah 21955, Saudi Arabia

\section{Corresponding author:}

Lisa A. Chiarello

Drexel University, Department of Physical Therapy and Rehabilitation Sciences, 1601 Cherry Street, Mail Stop 7502,

Philadelphia, PA 19102, USA 


\begin{abstract}
:
Aims: The primary aim of this study was to determine the effect of age, sex, gross motor, manual ability, and communication functions on the frequency and enjoyment of children's participation in family and recreational activities. The secondary aim was to determine the relationships between motor and communication functions and participation.

Methods: Participants were 694 children, 1.5 to 12 years old, with cerebral palsy (CP) and their parents across the US and Canada. Parents rated children's frequency and enjoyment of participation using the Child Engagement in Daily Life measure. Parents and therapists identified children's level of function using Gross Motor Function Classification System (GMFCS), Manual Ability Classification System (MACS), and Communication Function Classification System (CFCS).

Results: Differences in frequency and enjoyment of participation were found based on children's GMFCS, MACS, and CFCS levels but not age or sex. Children with higher gross motor, manual, and communication functions had higher frequency and enjoyment of participation, compared to children with lower functions. Frequency of participation was associated with GMFCS and CFCS levels whereas enjoyment of participation was only associated with CFCS level.

Implications: Knowledge of child's gross motor, manual ability, and communication functions of children with CP is important when setting goals and planning interventions for participation.
\end{abstract}




\section{Highlights:}

- For children with cerebral palsy between 1.5 to 12 years of age:

- Participation frequency differed by gross motor, manual, and communication function levels

- Communication and gross motor function levels contributed to frequency of participation

- Communication function level contributed to enjoyment of participation 


\section{Introduction:}

In the past two decades, there has been an increasing interest in understanding and promoting participation of children with cerebral palsy (CP). Although the World Health Organization (WHO) has broadly defined participation as "involvement in life situations" (WHO, 2007, p. 9), conceptual clarity of the WHO's definition is still open to debate in the pediatric participation literature. Recently, Imms and colleagues (2016) conducted a systematic review to explore variations in the language used to describe participation and they found two key terms that describe the participation construct, attendance and involvement. The authors further described attendance as the physical presence of the child in the activity, whereas involvement represents the "in-moment experience" of participation and includes elements of affect, motivation, and social connection (Imms et al., 2016). Chiarello (in press), however, suggests that involvement includes "affective, cognitive, and behavioral elements: how the person is feeling, thinking, and behaving". Nevertheless, there is a general consensus among researchers that participation is a multidimensional construct that can be influenced by a wide range of child, family, and environmental factors (Imms et al., 2016; Chiarello et al., 2016; Palisano et al., 2011; King et al., 2006).

An important outcome of rehabilitation services is to optimize children's participation in different life situations such as home, school, and in the community (Palisano et al., 2012). Participation in family and recreational activities provides avenues for children to play, learn skills, make friendships, and develop self-confidence and belonging (Chiarello et al., 2014; King, Petrenchik, Law, \& Hurley, 2009; Majnemer et al., 2008; King et al., 2006). Several child-related attributes influence participation of children with disabilities in family and recreational activities including age, sex, adaptive behavior, functional abilities, and impairments in body functions and structures (Chiarello et al., 2016; Imms, Reilly, Carlin, \& Dodd, 2009; King et al., 2006; Palisano et al., 2011; Shikako-Thomas, Majnemer, Law, \& 
Lach, 2008). Previous studies have focused primarily on measuring the diversity (range of activities) and frequency (how often) of participation and investigating its relationship with child-related attributes. However, less attention has been given to understand enjoyment of participation and child-related factors influencing it. Enjoyment of participation can be perceived as part of the emotional (affective) experience of participation (King et al., 2009; Chiarello, in press) as well as a proxy for the developmental and psychological benefits emerging from the participation experience (King et al., 2009).

Inconsistent findings have been found for the effect of child's age on the frequency and enjoyment of participation in family and recreational activities. Among children with $\mathrm{CP}$ (17 months to 6 years), children 3.5 to 4 years and older participated more often in activities compared to younger children (Chiarello et al., 2012; Chiarello et al., 2014; Law et al., 2012). Law et al. (2006) reported no age related differences in the total diversity and frequency of participation in recreational and leisure activities for children with physical disabilities 6 to 11 years; however, children 12 to 14 years participated in less number of activities and less frequently compared to children 6 to 11 years. Palisano et al. (2011) reported that among children with CP aged 6 to 12 years, younger age was associated with a higher frequency of participation. In regard to the enjoyment of participation, Chiarello et al. (2014) found that although children with CP 3.5 to 5 years of age enjoyed participation more than children 17 months to 2.5 years of age; on average parents reported that children across all age groups enjoyed their participation "very much" (Chiarello et al., 2014). For children with CP 6 to 12 years of age Majnemer et al. (2008) found that younger age was associated with more enjoyment of participation in informal activities.

In general, similarities in the frequency and enjoyment of participation between boys and girls with CP are more common than differences (Chiarello et al., 2012; Law et al., 2006; Palisano et al., 2011). Two studies reported that the total frequency of participation in family 
and recreational activities for children with CP 3 to 12 years of age did not differ by the child's sex (Chiarello et al., 2012; Palisano et al., 2011). However, other studies have found that girls with disabilities including $\mathrm{CP}, 2$ to 14 years of age, participated in a greater number of activities (Law et al., 2006; Law et al., 2012) and with higher frequency (Law et al., 2012) than boys. In addition, these studies also reported sex-related differences in the frequency of participation for specific dimensions of leisure and recreational activities (Law et al., 2006; Law et al., 2012). With regard to the enjoyment of participation, Majnemer et al. (2008) reported that for children with CP (6 to 12 years), female sex was associated with greater enjoyment of participation in formal and informal activities.

Several studies of children with CP have found that children with higher gross motor function participate in a greater diversity of leisure and recreational activities and do such activities more frequently compared with children with lower gross motor function (Chiarello et al., 2014; Chiarello et al., 2012; Imms, Reilly, Carlin, \& Dodd, 2008; Law et al., 2012; Palisano et al., 2011; Shikako-Thomas et al., 2008; Chiarello et al., 2016). However, Imms et al. (2008) found that diversity and frequency of participation for children with CP, 11 to 12 years of age, was similar across Gross Motor Function Classification System (GMFCS) levels except for children in level $\mathrm{V}$ who had a significantly lower diversity and frequency of participation. For enjoyment of participation, Chiarello et al. (2016) reported that gross motor function of children with CP (1.5 to 5 years) was not associated with enjoyment of participation.

Less attention has been given to understand the influence of children's manual ability on the frequency and enjoyment of participation. Chiarello et al. (2012) reported that scores on the Upper Extremity and Physical Function subscale of the Pediatrics Outcomes Data Collection Instrument (PODCI) were moderately correlated with frequency of participation for children with CP, 3-6 years old. In another study, the diversity of formal and informal 
participation were associated with Manual Ability Classification System (MACS) level for children with CP 11 to 12 years of age (Imms et al., 2009). In a related study, the diversity and frequency of participation did not differ for children in MACS levels I-IV but was lower for children in level V (Imms et al., 2008). The three studies provide some evidence that manual ability has influence on the diversity and frequency of participation for children with $\mathrm{CP}$; however, further investigation over a wider and more inclusive age range is warranted.

Several studies have reported the relationship between communication function and the diversity and frequency of participation of children with CP (Clarke et al., 2012; Imms et al., 2009; King et al., 2006; Palisano et al., 2011) but not enjoyment. These studies used different measures of communication and speech functions and found that higher communication/speech function is associated with a higher diversity and frequency of participation (Clarke et al., 2012; Imms et al., 2009; King et al., 2006; Palisano et al., 2011). The Communication Function Classification System (CFCS), validated in 2011 (Hidecker et al.), is now available to classify communication function of children with $\mathrm{CP}$.

Based on the research appraised, there are several areas where further research is needed. First, the effect of age and sex on a wide age range of children with $\mathrm{CP}$ has not been determined. Second, research is needed to understand the effect of manual ability on frequency and enjoyment of participation as well as the effect of gross motor function on enjoyment of participation. Third, we did not identify any studies that examined the effect of communication function on the frequency and enjoyment of participation in family and recreational activities. The primary purpose of this study, therefore, was to determine the effect of age, sex, gross motor, manual ability, and communication function levels on the frequency and enjoyment of participation in family and recreational activities for children with $\mathrm{CP}, 1.5$ to 12 years of age. The secondary purpose was to determine the association between children's level of function in gross motor, manual ability, and communication 
function classification systems and participation frequency and enjoyment. Knowledge of the effect of children's age, sex, gross motor, manual ability, and communication functions on frequency and enjoyment of participation in family and recreational activities of children with CP would inform families and service providers when developing an individualized plan of care to support children's desired participation.

\section{Methods}

\subsection{Design}

A cross sectional design was used. This study was a part of an ongoing multisite longitudinal prospective study that aims to create developmental trajectories and percentile curves for impairments in body structures/functions, associated health conditions and participation of children with CP.

\subsection{Participants}

The participants were a convenience sample of 694 children with $\mathrm{CP}$ and their parents. Participants were recruited from 4 regions in the United States (Greater Seattle, WA; Greater Philadelphia, PA; Greater Atlanta, GA, Greater Oklahoma City, OK) and 6 provinces in Canada (Newfoundland; Ontario; Manitoba; Saskatchewan; British Columbia; Nova Scotia). Children were excluded if they had a primary diagnosis other than $\mathrm{CP}$, gross motor delay without associated problems with muscle tone, balance, and active movement, or if they were wards of the state. Families who spoke English, French, or Spanish were eligible to participate in this study.

Demographic information on the children and their parents is presented in Table 1. Children were between 1.5 to 12 years of age with a mean age of 6 years $(S D=2.6), 55 \%$ were boys, and $71 \%$ were White. The motor and communication functions of children varied across all five levels of the GMFCS, MACS, and CFCS. Parents of the children were predominantly mothers $(88 \%)$ with a mean age of 37.7 years $(S D=7.9)$. Seventy-eight 
percent of the parents were White, $77 \%$ had an educational level greater than high school, and $58 \%$ were employed at the time of the study.

Ethical approval was obtained from each university's Institutional Review Boards and, when required, from the research ethics boards of sites through which recruitment and/or assessment took place. Prior to data collection, written informed consent was obtained from parents and assent was obtained from children when applicable.

\subsection{Measures}

\subsubsection{Child Engagement in Daily Life Measure}

Children's participation was measured using the family and recreational activities domain of the Child Engagement in Daily Life Measure (CEDL) (Chiarello et al., 2014). The family and recreational activities domain of the CEDL is an 11-item parent-reported measure that asks parents to rate their children's participation on two dimensions, frequency and enjoyment. Parents score participation on two 5-point Likert scales: how often does your child participate in an activity, i.e. frequency, $(5=$ very often; $4=$ often; $4=$ once in a while; $3=$ almost never; 1 = never); and how much does your child enjoy the activity, i.e. enjoyment, $(5=$ a great deal; $4=$ very much; $3=$ somewhat; $2=$ very little; $1=$ not at all $)$. Items of the measure represent categories of activities rather than discrete tasks. Examples of items include, family activities at home; outdoor play with children; and organized lessons. Under each item, there is a range of activity/routine examples; however, parents are instructed that these examples are not exhaustive and they can consider other activities in which their children participate. The CEDL measure can be obtained from CanChild website: (https://canchild.ca/en/research-in-practice/current-studies/move-play-studyunderstanding-determinants-of-motor-abilities-self-care-and-play-of-young-children-withcerebral-palsy).

Reliability and validity of the measure have been supported for children with CP 1.5 
to 5 years of age (Chiarello et al., 2014). Construct validity was established using the known groups methods to determine the variation of participation across age groups and gross motor function levels. It has been reported that young children (17 to 30 months) participate less often and enjoy participation less than older children (43 to 60 months) and children with higher gross motor function have higher participation scores than children with lower gross motor function. The internal consistency of the measure is high; Cronbach's alphas are 0.86 and 0.91 for frequency and enjoyment dimensions, respectively (Chiarello et al., 2014). The test-retest reliability for both frequency and enjoyment is acceptable, $\operatorname{ICC}_{(2,1)}=0.70$ (Chiarello et al., 2014). Palisano et al. (2014) investigated the change in children's participation in family and recreational activities over one year. The authors reported that the measure is sensitive to change over time for children in GMFCS level I (Cohen's $d=0.22$ ) and for children in GMFCS levels II-III (Cohen's d = 0.34) but not for children in GMFCS levels IV-V.

\subsubsection{Gross Motor Function Classification System (GMFCS)}

The GMFCS is a five-level classification system that is intended to classify children with CP (2-18 years) based on their self-initiated movement with emphasis on sitting, transferring, and mobility (Palisano et al., 1997; Palisano, Rosenbaum, Bartlett, \& Livingston, 2008). Content and construct validity and inter-rater reliability have been demonstrated. Inter-rater reliability is moderate $(\kappa=0.55)$ for children younger than 2 years and substantial $(\kappa=0.75)$ for children older than 2 years of age (Palisano et al., 1997). The age bands used in this study were 2-4 years, 4-6 years, and 6-12 years.

\subsubsection{Manual Ability Classification System (MACS):}

The MACS is a five-level classification system designed to classify children with CP, aged between 4-18 years, based on their ability to use their hands in daily life activities (Eliasson et al., 2006). The classification is primarily based on the quality of handling objects 
and the need of assistance to perform manual tasks in daily life activities. Evidence on content and construct validity has been reported (Eliasson et al., 2006). The inter-rater reliability of MACS for children between 4-18 years is high, ICC $=0.97$ (Eliasson et al., 2006). The inter-observer reliability for children under 2 years of age is moderate $(\kappa=0.55)$ and for children 2-5 years of age is good $(\kappa=0.67)$, respectively (Plasschaert, Ketelaar, Nijnuis, Enkelaar, \& Gorter, 2009).

\subsubsection{Communication Function Classification System (CFCS)}

The CFCS is a five-level classification system designed to classify the communication performance of children and youth with cerebral palsy 2-18 years of age (Hidecker et al., 2011). Children's communication function is classified based on the effectiveness of communication roles (sender or receiver), pace of communication (time and easiness of conveying and receiving messages), and type of conversational partner (familiar vs. unfamiliar). Evidence of content and construct validity has been reported (Hidecker et al., 2011). Inter-rater reliability between professionals is good $(\kappa=0.66)$ and between parents and professionals is moderate $(\kappa=0.49)$. Test-retest reliability is very good $(\kappa=0.82)$ (Hidecker et al., 2011).

All classification systems can be obtained at no cost from the following websites: GMFCS (www.canchild.ca); MACS (www.macs.nu); and CFCS (www.cfcs.us).

\subsection{Procedure}

Parents completed a family information form and the family and recreational activities domain of the CEDL at home or at their children's rehabilitation facility as part of their first visit for the On Track study. Parents and therapists independently classified their children's level of function on each of the three classification systems. If the classification levels differed, parent and therapist discussed the levels to reach a consensus. Parents' and therapists' classification of children's level of function were initially the same or consensus 
was reached following discussion 98\% of the time for GMFCS, $97 \%$ for MACS and $95 \%$ for CFCS. When consensus was not achieved, the parents' classification was used unless the therapist provided a reasonable justification (Bartlett, Galuppi, Palisano, \& McCoy, 2016). Data collection for this study occurred between April 2013 and February 2015.

\subsection{Data analysis}

Descriptive statistics were computed for all variables. Since interval level scores for the CEDL derived from Rasch analysis are valid only for children 18 to 60 months of age (Chiarello et al., 2014), all analyses were conducted using frequency and enjoyment mean raw scores. Our intent was to conduct a multi-factorial analysis to examine the interaction of the three classification systems on children's participation. The assumption of equality of sample cell size, however, was not met; many combinations among the three classification systems had a low cell size. Therefore, we conducted univariate comparative and correlational analyses.

Differences in the frequency and enjoyment of participation between four age groups (1.5-2.9, 3-5.9, 6-8.9, and 9-12 years) and five levels of each classification system were analyzed using one-way ANOVAs. Differences by sex were analyzed using independent ttests. When analyzing the differences across children's level of function for each classification system, the assumptions of homogeneity of variance and equality of sample sizes were not met. Therefore, the Welch's $F$-ratio was used instead of the ANOVA's $F$-ratio as it is considered a robust statistic against the heterogeneity of variance (Field, 2009, p. 379; Myers \& Well, 1995, p. 105-107). Additionally, Tamhane's T2 post hoc test, which accounts for unequal variance and unequal sample size, was used to investigate the pairwise comparisons within levels of function in each classification system (Muth, 2014, p. 261). Outliers were detected through visual inspection of the boxplots and represented only $0.6 \%$ to $1.9 \%$ of the frequency and enjoyment scores, depending on the analysis. We decided to retain 
them in the analyses due to the large sample size and our interest in reflecting the reported participation of children in our study.

To quantify the magnitude of the differences in the frequency and enjoyment of participation, effect size values were calculated using Cohen's d effect size for t-test analysis and eta-squared $\left(\eta^{2}\right)$ for f-ratio analyses (Lakens, 2013). The values of the effect sizes can be interpreted according to the following guidelines. For Cohen's $d, d=0.20$ indicates a small effect, $\mathrm{d}=0.50$ indicates a medium effect, and $\mathrm{d}=0.80$ indicates a large effect size. For etasquared: $\eta^{2}=0.01$ indicates a small effect, $\eta^{2}=0.06$ indicates a medium effect, and $\eta^{2}=0.14$ indicates a large effect size (Lakens, 2013).

Two simultaneous multiple regression analyses were performed to determine the association between children's levels of function in GMFCS, MACS, and CFCS and the frequency and enjoyment of participation. The assumptions of linearity, independence of errors, homoscedasticity, absence of influential points and normality of residuals were met. For all analyses, the alpha level was set at $p<.05$. The statistical software used for data analyses was SPSS (SPSS Statistics for Windows, Version 22.0. Armonk, NY: IBM Corp.)

\section{Results}

Descriptive statistics for children's participation by age and sex are presented in Table 2. Children with $\mathrm{CP}$, on average, participated in family and recreational activities often $(M=$ 4.0, $S D=0.65)$ and enjoyed these activities very much $(M=4.3, S D=0.57)$. There were no differences in the frequency of participation across the four age groups, $F(3,690)=2.54, p=$ .056. However, enjoyment of participation varied by child's age, $F(3,685)=4.13, \mathrm{p}=.006$, $\eta^{2}=0.02$, with children $3-5.9$ years of age $(M=4.4, S D=0.58)$ reported by their parents to enjoy activities more than children 1.5- 2.9 years of age $(M=4.2, S D=0.61)$. There were no differences in frequency and enjoyment of participation between boys and girls, $t(692)=-$ $0.26, p=.79$, and $t(687)=-1.77, p=.077$, respectively. 
Descriptive statistics for the frequency and enjoyment of participation of children grouped by level of function for each classification system are presented in Table 3 . Frequency and enjoyment of participation varied by the children's level of gross motor function (frequency: Welch's $F(4,280.75)=36.55, p<.001, \eta^{2}=0.20$; enjoyment: Welch's $\left.F(4,276.95)=7.59, p<.001, \eta^{2}=0.05\right)$, manual ability (frequency: Welch's $F(4,229.83)=$ $34.51, p<.001, \eta^{2}=0.20$; enjoyment: Welch's $\left.F(4,227.68)=10.71, p<.001, \eta^{2}=0.08\right)$, and communication function (frequency: Welch's $F(4,234.96)=52.44, p<.001, \eta^{2}=0.27$; enjoyment: Welch's $\left.F(4,225.63)=26.29, p<.001, \eta^{2}=0.18\right)$.

For gross motor function, pairwise comparisons indicated significant differences in frequency of participation between children in each level, $p<.001$, except between levels II and III. Children in GMFCS level I enjoyed participation more than children in levels IV and V. Children in levels II and III enjoyed participation more than children in level V, $p<.05$. For manual ability, children in levels I and II had a higher frequency of participation than children in levels III, IV and V, $p<.001$; children in level III had a higher frequency of participation than children in level V,p<.001. Children in MACS levels I and II enjoyed participation more than children in levels IV and $\mathrm{V}, p<.01$. For communication function, children's frequency and enjoyment of participation differed between each level, $p<.001$, except for levels II and III.

Correlations between children's level of function for each classification system and frequency and enjoyment of participation are provided in Table 4. Frequency and enjoyment of participation were negatively associated with children's level of function for each classification system (frequency $r=-0.43$ to -0.51 ; enjoyment $r=-0.22$ to -0.39 ). The three classification systems were positively intercorrelated ( $r=0.61$ to 0.77$)$. Positive correlation between frequency and enjoyment of participation was also observed $(r=0.70)$. 
The standardized regression coefficients for the regression models are presented in Table 5. Communication function and gross motor function levels explained $28 \%$ of the variance in frequency of participation, $F(3,690)=91.8, p<.001$, with the communication function level having the higher standardized beta. For enjoyment of participation, communication function level was the only significant variable in the regression model and explained $15 \%$ of the variance in enjoyment, $F(3,685)=42.13, p<.001$.

\section{Discussion}

As expected, frequency and enjoyment of participation for children with $\mathrm{CP}, 18$ months to 12 years of age, varied based on children's gross motor, manual ability, and communication function levels. Children with more functional abilities had higher frequency and enjoyment of participation in family and recreational activities than children with lower functional abilities. Although significant differences in frequency of participation were found between levels of function within the three classification systems, overall children classified in levels I to IV participated, on average, often whereas children in level V participated once in a while. For enjoyment of participation, we do not believe that the statistically significant differences within each classification system are clinically meaningful as children, on average, reported to enjoy their participation very much to a great deal.

A notable finding in our study is that for each classification system, children in level $\mathrm{V}$ had considerable variability in frequency and enjoyment of participation with some children participating almost never and enjoying their participation very little. Our finding that children in GMFCS and MACS level V had the lowest frequency of participation supports the suggestion that motor abilities might not be a limiting factor unless the child is classified as level V (Imms et al., 2008). Collectively, these findings suggest that children at level V may be at a disadvantage for participating in family and recreational activities and consequently failing to attain the potential benefits of such participation. 
Although we examined only children's gross motor, manual, and communication functions, the variance explained in children's frequency of participation by these functions, though modest, was relatively comparable to findings of studies that examined comprehensive models of child, family and environment/service determinants of participation (Majnemer et al., 2008; Imms et al., 2009; Palisano et al., 2011; Chiarello et al., 2012; Chiarello et al., 2016). In our study, the variance explained in frequency of participation was $28 \%$ whereas results of other studies explained 12 to $46 \%$ of the variance of participation (Majnemer et al., 2008; Imms et al., 2009; Palisano et al., 2011; Chiarello et al., 2012; Chiarello et al., 2016). However, the variance explained in enjoyment of participation (only $15 \%)$ found in our study was lower than variance explained in other multivariate studies, which ranged between 21 to 45\% (Majnemer et al., 2008; Chiarello et al., 2016). We acknowledge that direct comparisons are challenging because of the methodological variations across studies. However, research supports the notion that participation is a complex and individualized construct.

Our findings for communication function expand knowledge of determinants of participation of children with CP. Several studies have reported that children's gross motor function is moderately to strongly associated with frequency of participation (Imms et al., 2008; Palisano et al., 2011; Chiarello et al., 2016). Our finding indicates that children's communication function had a greater contribution than gross motor function in explaining frequency of participation. This finding suggests that higher communication function may especially benefit children with $\mathrm{CP}$ to participate more frequently in family and recreational activities. Our finding that only communication function was associated with enjoyment of participation suggests that children who have effective communication function may be at an advantage for enjoying their participation. The finding that gross motor function is not associated with enjoyment of participation is consistent with the results of a study by 
Chiarello et al. (2016). Children's motor abilities, while related to the frequency of participating in activities, are not necessarily related to emotional involvement such as sense of enjoyment. The fact that enjoyment is measured through parent-proxy report; however, needs to be considered, as parents may be able to interpret children's enjoyment easier if their child has higher communication function.

The finding that CFCS and GMFCS levels but not MACS level were associated with frequency of participation is partly attributable to the high correlations among the three classifications systems. In our study, the observed high correlation between the GMFCS and MACS levels created statistical redundancy to the regression model and therefore the MACS level did not contribute to the variance explained in the frequency of participation. Imms et al. (2009) previously reported that the MACS level but not the GMFCS level contributed to variance explained in diversity of participation. Although GMFCS and MACS are distinct motor classification systems, the interdependence and influence of gross motor function (e.g. head control and sitting) on manual function is a plausible explanation for the high correlation. Moreover, the moderate, but lower, correlation between CFCS level and GMFCS/MACS levels can be explained by the fact that communication function is more dependent on cognition than gross motor and manual functions. Although moderate to high correlation were found between children's levels of gross motor, manual ability, and communication function, nevertheless each classification system provides useful information for consideration of a child's strengths and how to optimize participation despite functional limitations.

The finding that participation did not differ by age and sex may be attributed to the participation measure (CEDL) used in our study, which asks parents to rate their children's participation on categories of activities rather than discrete tasks. Since each item on the CEDL provides a category of activities, this enables parents to consider all possible activities 
their children do and then rate them collectively. Although parents reported that children 3 to 5.9 years of age enjoyed participation more than children 1.5 to 2.9 years of age, we do not believe the difference is clinically meaningful as on average children in both groups enjoyed the activities very much. Another plausible explanation for lack of differences in participation based on children's age can be attributed to young age of children included in our study (1.5 to 12 years). Age-related differences in participation of children with $\mathrm{CP}$ may be more notable when children transition from childhood to adolescence (Orlin et al., 2009; Law et al., 2006). Our findings are also consistent with earlier research (Chiarello et al., 2012; Palisano et al., 2011) and findings by Law et al. (2006) that sex-related differences were evident primarily for specific dimensions of recreational participation but not for the total frequency or enjoyment of participation.

A limitation of the study is that we were unable to examine the combined effect of children's levels of gross motor, manual ability, and communication functions on frequency and enjoyment of participation in family and recreational activities. Additionally, we did not account for other child or environmental factors that may have influenced participation. We examined the total participation scores but did not analyze specific types/categories of participation. Our current study only included children with CP and therefore the findings may not be generalized to children with other disabilities. We recommend the use of case series research to examine and describe child, family, and environmental factors that may influence participation in family and recreational activities for children with $\mathrm{CP}$ and other disabilities across different combinations of gross motor, manual ability, and communication function levels.

Service providers are encouraged to use the CEDL to assess children's current participation and engage children and families in discussions about their priorities for participation-based goals. Given the complexity of participation, service providers are 
encouraged to consider and discuss with the child, family, and other team members aspects of the child and environment that may be facilitators or barriers to participation. In addition to supporting children's motor function, we encourage providers to address communication function specific to goals for participation. We recommend a solution-focused approach to enhance children's communication through practice of interactions with others in real-life contexts, provision of supports, adaptations of activities, and environmental modifications to lessen the potential barriers to participation. Children with severe limitations in gross motor, manual, and communication functions (level V) may particularly require coordinated, interdisciplinary services to understand and address their unique needs. Providers can support children, parents, and community leaders by sharing information, providing consultation, and assisting families to obtain necessary resources to enable their children's participation in family and recreational activities (Palisano et al., 2012). Further research is warranted to systematically examine the variability in participation of children at level V of the classification systems. Research is also needed to examine the involvement aspect of participation (i.e. affective, cognitive, and behavioral elements of participation) for children with $\mathrm{CP}$ and other disabilities. We believe that it is important that researchers focus on investigating the effectiveness of intervention approaches to support children's participation.

\section{Conclusion:}

The frequency and enjoyment of participation in family and recreational activities for children 18 months to 12 years of age with $\mathrm{CP}$, across the United States and Canada, differed based on the children's level of gross motor function, manual ability, and communication function, but not age or sex. Children with higher functional abilities participated more frequently and enjoyed their participation more compared to children with lower functional abilities. However, differences in the enjoyment of participation across children's levels of function within each of the three classification systems were not clinically meaningful. 
Among children's motor and communication functions, communication function contributed to the variance explained in frequency of participation more than the gross motor and was the only function that contributed to the enjoyment of participation. The findings of this study emphasize the importance of recognizing children's strengths and challenges in gross motor, manual ability, and communication functions for supporting participation in family and recreational activities. Given the complex and individualized nature of participation of children with $\mathrm{CP}$, comprehensive understanding of child, family, and environmental factors is necessary for setting goals and planning interventions for participation. 


\section{Acknowledgment:}

This project was supported by Canadian Institutes of Health Research (MOP-119276) and Patient-Centered Outcomes Research Institute (5321). We acknowledge the On Track study team, participating sites, children and their families.

\section{Disclaimer:}

The statements presented in this work are solely the responsibility of the authors and do not necessarily represent the views of the Patient-Centered Outcomes Research Institute (PCORI), its Board of Governors or Methodology Committee. 


\section{References:}

Bartlett, D. J., Galuppi, B., Palisano, R. J., \& McCoy, S. W. (2016). Consensus classifications of gross motor, manual ability, and communication function classification systems between therapists and parents of children with cerebral palsy. Developmental Medicine \& Child Neurology, 58(1), 98-99. doi:10.1111/dmcn.12933

Chiarello, L. A., Palisano, R., Orlin, M. N., Chang, H. J., Begnoche, D., \& An, M. (2012). Understanding participation of preschool-age children with cerebral palsy. Journal of Early Intervention, 1053815112443988.

Chiarello, L. A., Palisano, R. J., McCoy, S. W., Bartlett, D. J., Wood, A., Chang, H. J., . . Avery, L. (2014). Child engagement in daily life: a measure of participation for young children with cerebral palsy. Disability \& Rehabilitation, 36(21), 1804-1816. doi:10.3109/09638288.2014.882417

Chiarello, L. A., Bartlett, D. J., Palisano, R. J., McCoy, S. W., Fiss, A. L., Jeffries, L., \& Wilk, P. (2016). Determinants of participation in family and recreational activities of young children with cerebral palsy. Disability and Rehabilitation, 38(25), 2455-2468. doi: $10.3109 / 09638288.2016 .1138548$

Chiarello, L. A., (in press). Excellence in Promoting Participation: Striving for the 10 Cs. Pediatric Physical Therapy Journal.

Clarke, M., Newton, C., Petrides, K., Griffiths, T., Lysley, A., \& Price, K. (2012). An examination of relations between participation, communication and age in children with complex communication needs. Augment Altern Commun, 28(1), 44-51. doi:10.3109/07434618.2011.653605

De Muth, J. E. (2014). Basic statistics and pharmaceutical statistical applications: CRC Press. 
Eliasson, A.-C., Krumlinde-Sundholm, L., Rösblad, B., Beckung, E., Arner, M., Öhrvall, A.M., \& Rosenbaum, P. (2006). The Manual Ability Classification System (MACS) for children with cerebral palsy: scale development and evidence of validity and reliability. Developmental Medicine \& Child Neurology, 48(07), 549-554. doi: $10.1017 / \mathrm{S} 0012162206001162$

Field, A. (2009). Discovering statistics using SPSS, $3^{\text {rd }}$ Edition. London, UK: Sage Publications.

Hidecker, M. J. C., Paneth, N., Rosenbaum, P. L., Kent, R. D., Lillie, J., Eulenberg, J. B., . . . Evatt, M. (2011). Developing and validating the Communication Function Classification System for individuals with cerebral palsy. Developmental Medicine \& Child Neurology, 53(8), 704-710. doi: 10.1111/j.1469-8749.2011.04035.x.

Imms, C., Adair, B., Keen, D., Ullenhag, A., Rosenbaum, P. and Granlund, M. (2016), 'Participation': a systematic review of language, definitions, and constructs used in intervention research with children with disabilities. Dev Med Child Neurol, 58: 29_ 38. doi:10.1111/dmcn.12932

Imms, C., Reilly, S., Carlin, J., \& Dodd, K. (2008). Diversity of participation in children with cerebral palsy. Developmental Medicine \& Child Neurology, 50(5), 363-369. doi: 10.1111/j.1469-8749.2008.02051.x

Imms, C., Reilly, S., Carlin, J., \& Dodd, K. J. (2009). Characteristics influencing participation of Australian children with cerebral palsy. Disability \& Rehabilitation, 31(26), 2204-2215. doi:10.3109/09638280902971406

King, G., Law, M., Hanna, S., King, S., Hurley, P., Rosenbaum, P., ... \& Petrenchik, T. (2006). Predictors of the leisure and recreation participation of children with physical disabilities: a structural equation modeling analysis. Children's Health Care, 35(3), 209-234. doi: 10.1207/s15326888chc3503_2 
King, G., Petrenchik, T., Law, M., \& Hurley, P. (2009). The Enjoyment of Formal and Informal Recreation and Leisure Activities: A comparison of school-aged children with and without physical disabilities. International Journal of Disability, Development and Education, 56(2), 109-130. doi: 10.1080/10349120902868558

Lakens, D. (2013). Calculating and Reporting Effect Sizes to Facilitate Cumulative Science: A Practical Primer for t-tests and ANOVAs. Frontiers in Psychology, 4. doi:10.3389/fpsyg.2013.00863

Law, M., King, G., King, S., Kertoy, M., Hurley, P., Rosenbaum, P., . . Hanna, S. (2006). Patterns of participation in recreational and leisure activities among children with complex physical disabilities. Developmental Medicine \& Child Neurology, 48(5), 337-342. doi:10.1017/s0012162206000740

Law, M., King, G., Petrenchik, T., Kertoy, M., \& Anaby, D. (2012). The assessment of preschool children's participation: internal consistency and construct validity. Physical \& Occupational Therapy in Pediatrics, 32(3), 272-287. doi:10.3109/01942638.2012.662584

Majnemer, A., Shevell, M., Law, M., Birnbaum, R., Chilingaryan, G., Rosenbaum, P., \& Poulin, C. (2008). Participation and enjoyment of leisure activities in school-aged children with cerebral palsy. Developmental Medicine \& Child Neurology, 50(10), 751-758. doi:10.1111/j.1469-8749.2008.03068.x

Myers, J. L., \& Well, A. (1995). Research design and statistical analysis: Lawrence Erlbaum Associates.

Orlin, M. N., Palisano, R. J., Chiarello, L. A., KANG, L. J., Polansky, M., Almasri, N., \& Maggs, J. (2010). Participation in home, extracurricular, and community activities 
among children and young people with cerebral palsy. Developmental Medicine \& Child Neurology, 52(2), 160-166. doi: 10.1111/j.1469-8749.2009.03363.x

Palisano, R., Rosenbaum, P., Walter, S., Russell, D., Wood, E., \& Galuppi, B. (1997). Development and reliability of a system to classify gross motor function in children with cerebral palsy. Developmental Medicine \& Child Neurology, 39(4), 214-223. doi: 10.1111/j.1469-8749.1997.tb07414.x

Palisano, R. J., Rosenbaum, P., Bartlett, D., \& Livingston, M. H. (2008). Content validity of the expanded and revised Gross Motor Function Classification System. Developmental Medicine \& Child Neurology, 50(10), 744-750. doi:10.1111/j.14698749.2008.03089.x

Palisano, R. J., Chiarello, L. A., Orlin, M., Oeffinger, D., Polansky, M., Maggs, J., . . . Gorton, G. (2011). Determinants of intensity of participation in leisure and recreational activities by children with cerebral palsy. Developmental Medicine \& Child Neurology, 53(2), 142-149. doi:10.1111/j.1469-8749.2010.03819.x

Palisano, R. J., Chiarello, L. A., King, G. A., Novak, I., Stoner, T., \& Fiss, A. (2012). Participation-based therapy for children with physical disabilities. Disability and Rehabilitation, 34(12), 1041-1052. doi: 10.3109/09638288.2011.628740

Palisano, R. J., Chiarello, L. A., McCoy, S. W., Bartlett, D., \& An, M. (2014). Use of the Child Engagement in Daily Life and Ease of Caregiving for Children to Evaluate Change in Young Children with Cerebral Palsy. Physical \& Occupational Therapy in Pediatrics. doi:10.3109/01942638.2014.907221

Plasschaert, V. F., Ketelaar, M., Nijnuis, M. G., Enkelaar, L., \& Gorter, J. W. (2009). Classification of manual abilities in children with cerebral palsy under 5 years of age: how reliable is the Manual Ability Classification System?. Clinical rehabilitation, 23(2), 164-170. doi: 10.1177/0269215508098892 
Shikako-Thomas, K., Majnemer, A., Law, M., \& Lach, L. (2008). Determinants of participation in leisure activities in children and youth with cerebral palsy: systematic review. Physical \& Occupational Therapy in Pediatrics, 28(2), 155-169. doi: $10.1080 / 01942630802031834$

World Health Organization. (2007). International Classification of Functioning, Disability, and Health: Children \& Youth Version: ICF-CY. World Health Organization. 
Understanding Participation of Children with Cerebral Palsy in Family and Recreational Activities

Table 1

Child and parent demographic characteristics

\begin{tabular}{|c|c|c|}
\hline & & $\begin{array}{l}\text { Participants } \\
\mathrm{N}=694(\%)\end{array}$ \\
\hline Child age (years) $(n=694)$ & Mean (SD) & $6(2.6)$ \\
\hline \multirow[t]{2}{*}{ Gender $(n=694)$} & Boy & $383(55.2 \%)$ \\
\hline & Girl & $311(44.8)$ \\
\hline \multirow[t]{2}{*}{ Child ethnicity $(\mathrm{n}=692)^{*}$} & Non-Hispanic & $644(93.0 \%)$ \\
\hline & Hispanic & $48(7.0 \%)$ \\
\hline \multirow[t]{5}{*}{ Child race $(\mathrm{n}=682) *$} & American Indian/Alaska Native & $14(2.0 \%)$ \\
\hline & Asian & $40(5.9 \%)$ \\
\hline & Black/African American & $60(8.8 \%)$ \\
\hline & White & $488(71.6 \%)$ \\
\hline & Multiracial & $80(11.7 \%)$ \\
\hline \multirow[t]{5}{*}{ Child GMFCS $(n=694)$} & Level I & $223(32.1 \%)$ \\
\hline & Level II & $155(22.3 \%)$ \\
\hline & Level III & $81(11.7 \%)$ \\
\hline & Level IV & $131(18.9 \%)$ \\
\hline & Level V & $104(15.0 \%)$ \\
\hline \multirow[t]{5}{*}{ Child MACS $(n=694)$} & Level I & $140(20.2 \%)$ \\
\hline & Level II & $273(39.3 \%)$ \\
\hline & Level III & $104(15.0 \%)$ \\
\hline & Level IV & $117(16.9 \%)$ \\
\hline & Level V & $60(8.6 \%)$ \\
\hline \multirow[t]{5}{*}{ Child CFCS $(n=694)$} & Level I & $256(36.9 \%)$ \\
\hline & Level II & $122(17.6 \%)$ \\
\hline & Level III & $132(19.0 \%)$ \\
\hline & Level IV & $129(18.6 \%)$ \\
\hline & Level V & $55(7.9 \%)$ \\
\hline \multirow{5}{*}{$\begin{array}{l}\text { Distribution of Involvement } \\
(\mathrm{n}=691)^{*}\end{array}$} & Monoplegia & $7(1.0 \%)$ \\
\hline & Hemiplegia & $194(28.1 \%)$ \\
\hline & Diplegia & $182(26.3 \%)$ \\
\hline & Triplegia & $39(5.6 \%)$ \\
\hline & Quadriplegia & $269(39.0 \%)$ \\
\hline $\begin{array}{l}\text { Parent's age in years } \\
(\mathrm{n}=684)^{*}\end{array}$ & Mean (SD) & $37.7(7.9)$ \\
\hline \multirow{3}{*}{$\begin{array}{l}\text { Parent relationship to child (n } \\
=693)^{*}\end{array}$} & Mother & $612(88.3 \%)$ \\
\hline & Father & $48(6.8 \%)$ \\
\hline & $\begin{array}{l}\text { Others (indicated as grandparents and } \\
\text { foster mother) }\end{array}$ & $33(4.1 \%)$ \\
\hline \multirow{6}{*}{$\begin{array}{l}\text { Total household income }(\mathrm{n}= \\
690)^{*}\end{array}$} & $<\$ 30,000$ & $100(14.5 \%)$ \\
\hline & $\$ 30,000-\$ 44,999$ & $57(8.3 \%)$ \\
\hline & $\$ 45,000-\$ 59,999$ & $50(7.2 \%)$ \\
\hline & $\$ 60,000-\$ 74,999$ & $77(11.2 \%)$ \\
\hline & $\geq \$ 75,000$ & $303(43.9 \%)$ \\
\hline & Prefer not to answer & $103(14.9 \%)$ \\
\hline \multirow[t]{3}{*}{ Parent education $(\mathrm{n}=689) *$} & High school or less & $157(22.8 \%)$ \\
\hline & $\begin{array}{l}\text { Community college diploma; technical } \\
\text { degree / associate degree }\end{array}$ & $208(30.2 \%)$ \\
\hline & University/Graduate Degree & $324(47 \%)$ \\
\hline
\end{tabular}

\footnotetext{
* Based on available data provided by participants
} 
Understanding Participation of Children with Cerebral Palsy in Family and Recreational Activities

Table 2

Frequency and enjoyment of participation by sex and age groups

\begin{tabular}{|c|c|c|}
\hline & $\begin{array}{l}\text { Frequency } \\
\text { M(SD) }\end{array}$ & $\begin{array}{l}\text { Enjoyment } \\
\mathrm{M}(\mathrm{SD})\end{array}$ \\
\hline \multicolumn{3}{|l|}{ Sex } \\
\hline Boys $(n=383)$ & $4.1(0.64)$ & $4.3(0.58)$ \\
\hline Girls $(n=311)$ & $4.0(0.67)$ & $4.4(0.56)$ \\
\hline$p$ value & $p=.79$ & $p=0.77$ \\
\hline \multicolumn{3}{|l|}{ Age groups } \\
\hline 1.5 to 2.9 years $(n=129)$ & $3.9(0.68)$ & $4.2(0.61)$ \\
\hline 3 to 5.9 years $(n=210)$ & $4.1(0.65)$ & $4.4(0.58)$ \\
\hline 6 to 8.9 years $(\mathrm{n}=239)$ & $4.0(0.64)$ & $4.4(0.52)$ \\
\hline 9 to 12 years $(n=116)$ & $3.9(0.63)$ & $4.3(0.61)$ \\
\hline$p$ value & $p=.056$ & $p=.006$ \\
\hline
\end{tabular}


Understanding Participation of Children with Cerebral Palsy in Family and Recreational Activities

Table 3

The frequency and enjoyment of participation across three function classification systems.

\begin{tabular}{|c|c|c|c|c|c|c|}
\hline & \multicolumn{2}{|l|}{ GMFCS } & \multicolumn{2}{|l|}{ MACS } & \multicolumn{2}{|l|}{ CFCS } \\
\hline & Frequency & Enjoyment & Frequency & Enjoyment & Frequency & Enjoyment \\
\hline & $\mathrm{M}(\mathrm{SD})$ & $\mathrm{M}(\mathrm{SD})$ & $\mathrm{M}(\mathrm{SD})$ & $\mathrm{M}(\mathrm{SD})$ & $\mathrm{M}(\mathrm{SD})$ & M(SD) \\
\hline Level I & $4.3(0.53)$ & $4.5(0.46)$ & $4.2(0.57)$ & $4.5(0.47)$ & $4.3(0.52)$ & $4.6(0.43)$ \\
\hline Level II & $4.1(0.54)$ & $4.4(0.52)$ & $4.2(0.51)$ & $4.4(0.48)$ & $4.1(0.48)$ & $4.4(0.49)$ \\
\hline Level III & $4.0(0.57)$ & $4.4(0.47)$ & $3.9(0.63)$ & $4.3(0.59)$ & $3.9(0.55)$ & $4.4(0.49)$ \\
\hline Level IV & $3.7(0.64)$ & $4.3(0.63)$ & $3.7(0.59)$ & $4.2(0.59)$ & $3.7(0.63)$ & $4.1(0.61)$ \\
\hline Level V & $3.5(0.69)$ & $4.1(0.75)$ & $3.4(0.81)$ & $3.9(0.84)$ & $3.2(0.70)$ & $3.7(0.78)$ \\
\hline$p$ value & $p<.001$ & $p<.001$ & $p<.001$ & $p<.001$ & $p<.001$ & $p<.001$ \\
\hline
\end{tabular}


Understanding Participation of Children with Cerebral Palsy in Family and Recreational Activities

Table 4

Correlations between frequency and enjoyment and classification systems

\begin{tabular}{lllll}
\hline & Frequency & Enjoyment & GMFCS & MACS \\
\hline Frequency & & & & \\
Enjoyment & $0.70 *$ & & & \\
GMFCS & $-0.44 *$ & $-0.22 *$ & $0.77 *$ & \\
MACS & $-0.43 *$ & $-0.27 *$ & $0.61 *$ & $0.70 *$ \\
CFCS & $-0.51 *$ & $-0.39 *$ &
\end{tabular}

* Correlation is significant at $p<0.01$ (2-tailed). 
Understanding Participation of Children with Cerebral Palsy in Family and Recreational Activities

Table 5

Regression models for the frequency and enjoyment of participation

\begin{tabular}{lll}
\hline Frequency of participation $(\mathrm{n}=694)$ & & \\
\hline Variable & Standardized Beta & $<.001$ \\
CFCS & -.39 & $<.001$ \\
GMFCS & -.19 & 0.83 \\
MACS & -.01 & \\
Adjusted $\mathrm{R}^{2}=0.28, p<.001$ & & p value \\
\hline Enjoyment of participation $(\mathrm{n}=689)$ & & $<.001$ \\
\hline Variable & Standardized Beta & 0.46 \\
CFCS & -0.41 & 0.80 \\
GMFCS & 0.04 & \\
MACS & -0.02 & \\
Adjusted $\mathrm{R}^{2}=0.15, p<.001$ & & \\
\hline
\end{tabular}

